\begin{tabular}{|c|c|c|}
\hline Beitr. Ent. & Keltern & ISSN 0005-805X \\
\hline $\mathbf{5 7}(2007) 2$ & S. $277-283$ & 21.12 .2007 \\
\hline
\end{tabular}

\title{
Three new species of the genus Anomala Samouelle, 1819 from Borneo of the fulvofusca-species group
}

\section{(Coleoptera: Scarabaeidae: Rutelinae)}

With 14 figures

\section{CARSTEN ZorN}

\section{Summary}

Anomala parastasioides sp. n., Anomala matangensis sp. n. and Anomala pumiloides sp. n. are described from Borneo. Together with Anomala fulvofusca OHAus, 1915 and Anomala pumilis OHAUs these three new species form a species group which is mainly based on male genitalia characters.

\section{Zusammenfassung}

Anomala parastasioides sp. n., Anomala matangensis sp. n. und Anomala pumiloides sp. n. von Borneo werden beschrieben. Zusammen mit Anomala fulvofusca OHAus, 1915 und Anomala pumilis OHAus, 1932 bilden sie eine hauptsächlich auf männlichen Genitalmerkmalen basierende Artengruppe.

Key words

Coleoptera, Scarabaeidae, Rutelinae, Anomala, fulvofusca-species group, taxonomy, new species, Oriental region, Borneo

New species

Anomala parastasioides sp. n., Anomala matangensis sp. n., Anomala pumiloides sp. n.

\section{Introduction}

Among the undetermined Rutelinae material of the British Museum (Natural History) in London two new species of Anomala, SAMOUELLE, 1819 from Borneo were found, which are closely related to $A$. fulvofusca OHaus, 1915 and $A$. pumilis OHaus, 1932. Moreover, another new species similar to $A$. pumilis was received from Mr. Milan Nikodým (Prague). The description of these three new species and a discussion on their systematic position is given in the following paper.

\section{Material}

The material is deposited in the following collections:

BMNH Natural History Museum, London

CCZ Collection C. Zorn, Gnoien (Germany) 


\section{Descriptions}

Anomala parastasioides sp. n. (Fig. 1)

Holotype. ơ "SABAH: Tawai Plat. 1300ft, 8m. S. Telupid 8.ix.1977| At light | M. E. Bacchus B.M. 1978-48 | HOLOTYPUS Anomala parastasioides sp. n. det. Zorn, 2007” (BMNH).

\section{Description:}

Body shape. Length: $10.3 \mathrm{~mm}$, width: $6.0 \mathrm{~mm}$; oval, stout, and convex. Color. Head dark reddish; pronotum, scutellum and elytra yellowish brown with two separated longitudinal black discal patches on the pronotum, the latter not reaching the anterior or posterior margin; elytral pattern as follows: humeral protuberance and the complete anterior margin black; a broad black longitudinal patch along the suture which is dilated before but not reaching the apex; sutural margin itself narrowly reddish; propygidium and a transverse triangular patch at the base of the pygidium dark reddish to black; remaining part of the pygidium yellowish brown; underside including antennae and femora yellowish brown; metasternum somewhat blackened; tibiae and tarsi dark reddish brown; abdominal sternites black with a reddish distal margin. Head. Clypeus subrectangular, strongly reflexed; anterior angles broadly rounded; surface with fine punctures densely covered; frons with larger, somewhat umbilicate punctures; punctures smaller and less dense towards vertex. Pronotum. Width 1.61 times length, broadest somewhat behind the middle; sides evenly curved and strongly convergent towards the acute anterior angles; posterior angles broadly rounded; basal stria not interrupted; punctures moderately fine and rather sparse on the disc, gradually larger and more dense towards the lateral margins. Elytra. With deeply impressed, coarse and somewhat umbilicate punctures arranged in regular striae mixed with sparse micropunctation; primary costae not elevated; subsutural, second and third interstice (the intervals between primary costae) with one secondary row of punctures, the one of the subsutural interstice irregularly duplicated behind the scutellum; the three inner primary striae weakly sulcate at the apex; humeral protuberance prominent and smooth. Pygidium. Convex in profile; punctures umbilicate and deeply impressed, moderately fine at the base, gradually coarser and denser towards the hind margin. Metasternum. Disc smooth and shining, weakly sulcate; lateral parts gradually more densely and coarsely punctured, with rather short and not dense yellowish setae. Abdominal sternites. Densely punctured with some irregular smooth areas; punctures moderately coarse, sometimes transversely confluent; with a transverse series of yellowish semierect setae; distal margin of the last sternite deeply emarginate. Protibia. Bidentate, lateral and terminal teeth rather short and blunt, but apparently somewhat worn out; terminal articulated spine very short, about 1.5 times as long as wide. Metatibia. Moderately slender, 3.1 times as long as wide, slightly fusiform. Claws. External middle claw and internal fore claw cleft; the latter with a very small spine-shaped upper branch; lower branch much broader and longer, with an obtuse angle at its inner margin and excised before the strongly pointed apex (Fig. 14). Aedeagus. See figs 4, 5.

\section{Diagnosis:}

Anomala parastasioides sp. n. is easily distinguishable from its relatives, $A$. fulvofusca, $A$. matangensis, A. pumilis and $A$. pumiloides, by the remarkable coloration pattern with distinct black patches on pronotum and elytra and the different structure of the aedeagus with hirsute parameres. Moreover, A. parastasioides sp. n. is distinctly bigger than the other species.

Etymology: The species name is referring to the superficial resemblance of $A$. parastasioides to some small species of the Ruteline genus Parastasia Westwood, 1842. 

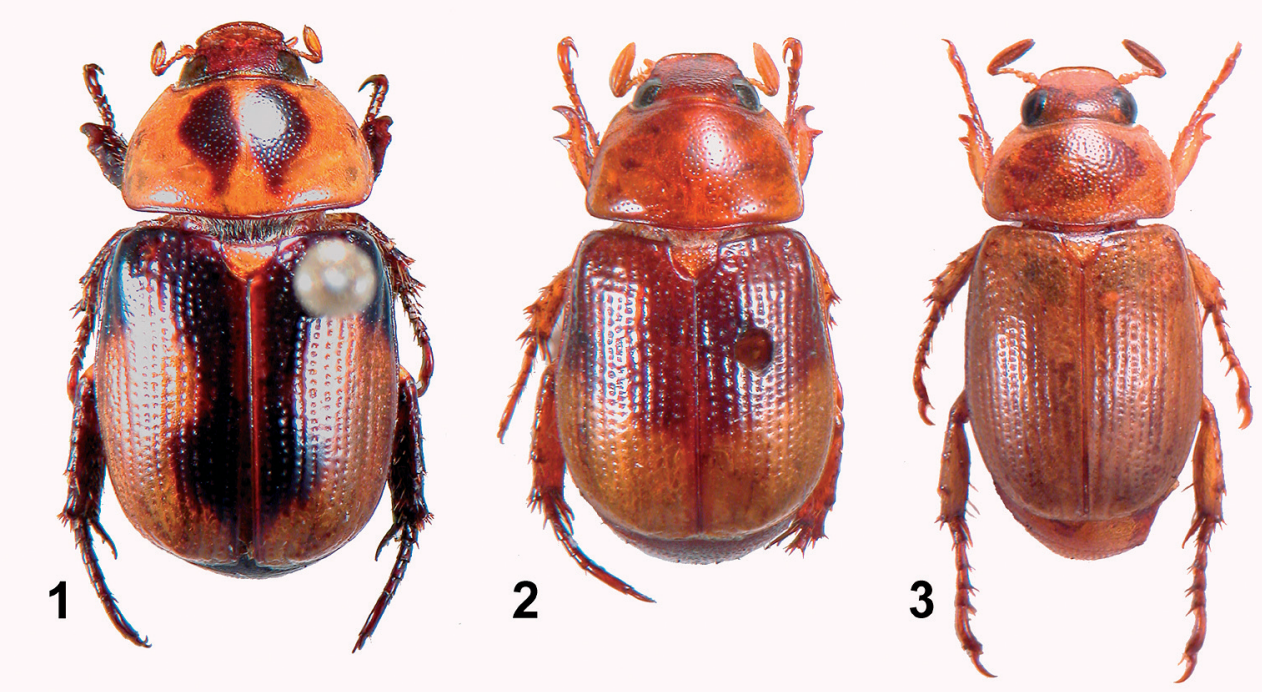

Fig. 1: Anomala parastasioides (holotype). - Fig. 2: Anomala matangensis (holotype). - Fig. 3: Anomala pumiloides (holotype).

Anomala matangensis sp. n. (Fig. 2)

Holotype. ơ "Za 21 | Mt. Matanga, W. Sarawak, G. E. Bryant. 16.II.14. | G. Bryant Coll. B.M.1926-86. | HOLOTYPUS Anomala matangensis sp. n. det. Zorn, 2007” (BMNH).

\section{Description:}

Body shape. Length: $7.8 \mathrm{~mm}$, width: $4.3 \mathrm{~mm}$; elongate oval, dilated behind; strongly convex. Color. Head reddish brown; pronotum reddish brown on the disc, yellowish brown towards the lateral margins; scutellum yellowish; elytra dark brown, with the apical part broadly pale yellow; sutural margin reddish; underside including femora and antennae pale yellowish; propygidium, pygidium, abdominal sternites, tibiae and tarsi reddish brown. Head. Clypeus trapezoid, anterior angles rounded; anterior margin reflexed; punctures moderately fine; frons transversely punctured, somewhat rugose; punctures more fine and sparse towards vertex. Pronotum. Width 1.56 times length; in dorsal view broadest at its base; lateral margins straight and subparallel posteriorly, curved and convergent in the anterior third; anterior angles acute; posterior angles rounded; basal stria complete; whole surface with fine and rather sparse punctation. Elytra. With impressed, coarse and somewhat umbilicate punctures, arranged in regular striae; sparse micropunctation intermixed; primary costae not elevated; subsutural, second and third interstice with one secondary row of punctures, the one of the subsutural interstice irregularly duplicated behind the scutellum; the three inner primary striae weakly sulcate at the apex; humeral and apical protuberance distinct, but not very prominent. Pygidium. Moderately fine punctured; punctures somewhat oblong near the distal margin. Metasternum. Disc sulcate, with minute sparse punctures; towards the lateral margin with very dense, umbilicate punctures and short yellowish setae. Abdominal sternites. Densely, sometimes confluently punctured; with a transverse series of short yellowish setae. Protibia. With a long, acute lateral tooth and a long pointed terminal tooth which is strongly curved outwards; terminal articulated spine short, about 2 times as long as wide. Metatibia. 2.5 times as long as wide, slightly fusiform. Claws. External middle claw and internal front claw cleft; the upper branch of the latter very small and spine-shaped; the lower branch 
much broader and longer, with an obtuse angle at its inner margin and distinctly excised before the strongly pointed apex. Aedeagus. See figs 6, 7.

\section{Diagnosis:}

Anomala matangensis is very similar to A. fulvofusca but can be distinguished by the different aedeagus (Figs 5, 6) and the coloration as described above. The degree of variation of the coloration pattern, however, is uncertain as long as no further material is available.

Etymology: The species epithet is referring to the type locality, Mt. Matang in western Sarawak, Borneo.

Anomala pumiloides sp. n. (Fig. 3)

Holotype. o* "BORNEO-SABAH Banjaran Maitland Sapulut 22.-24.5.1995 Ivo Jeniš leg. | HOLOTYPUS Anomala pumiloides sp. n. det. Zorn, 2007” (CCZ).

Paratypes. 1 o, 1 우 “BORNEO-SABAH Banjaran Maitland Sapulut 22.-24.5.1995 Ivo Jeniš leg.

| PARATYPUS Anomala pumiloides sp. n. det. Zorn, 2007” (CCZ).

\section{Description:}

Body shape. Length: 7.0-7.5 mm, width: 3.3-3.7 mm; elongate oval; subparallel posteriorly; strongly convex. Color. Entirely yellowish brown; head between the eyes, some indistinct transverse patches on the disc of the pronotum and the entire abdomen in the male sex darker brown. Head. Clypeus trapezoid; anterior angles rounded; anterior margin reflexed; punctures moderately fine; frons densely and sometimes confluently punctured; punctures gradually finer and more sparse towards the vertex. Pronotum. Width 1.64 times length; in dorsal view lateral margin evenly curved and strongly converging towards the acute anterior angles; broadest somewhat behind the middle; posterior angles rounded; basal stria complete; the whole surface covered with moderately sized, umbilicate punctures. Elytra. With rather coarse and umbilicate punctures arranged in regular striae and intermixed irregular, sparse micropunctation; primary costae not elevated; subsutural, second and third interstice with one secondary row of punctures, the one of the subsutural interstice irregularly duplicated at its base; the three inner primary striae weakly sulcate at the apex; humeral protuberance indistinct. Pygidium. Densely covered with coarse, umbilicate punctures. Metasternum. Disc smooth with a longitudinal impression; lateral part with dense umbilicate punctures and indistinct, short setosity. Abdominal sternites. Densely, sometimes confluently punctured; with a transverse series of sparse short yellowish setae. Protibia. With a long acute lateral tooth and a long pointed terminal tooth which is strongly curved outwards; terminal articulated spine about 5 times as long as wide. Metatibia. 2.8 times as long as wide, weakly fusiform. Claws. External middle claw and internal front claw cleft; upper branch of the latter very small and spine-shaped; the lower branch much more broad and long, somewhat dilated at its inner margin; with a strongly pointed apex. Aedeagus. See figs 8, 9.

\section{Diagnosis:}

Anomala pumiloides is very similar to $A$. pumilis but can easily be distinguished by the larger elongated body shape, the strongly rounded sides and the more coarse punctation of the pronotum and the less reflexed clypeus. Moreover, the hind tibiae are more fusiform in $A$. pumilis and the parameres are distinctly longer (Figs 10,11).

Etymology: The species name is referring to the notable resemblance of the new species to A. pumilis. 

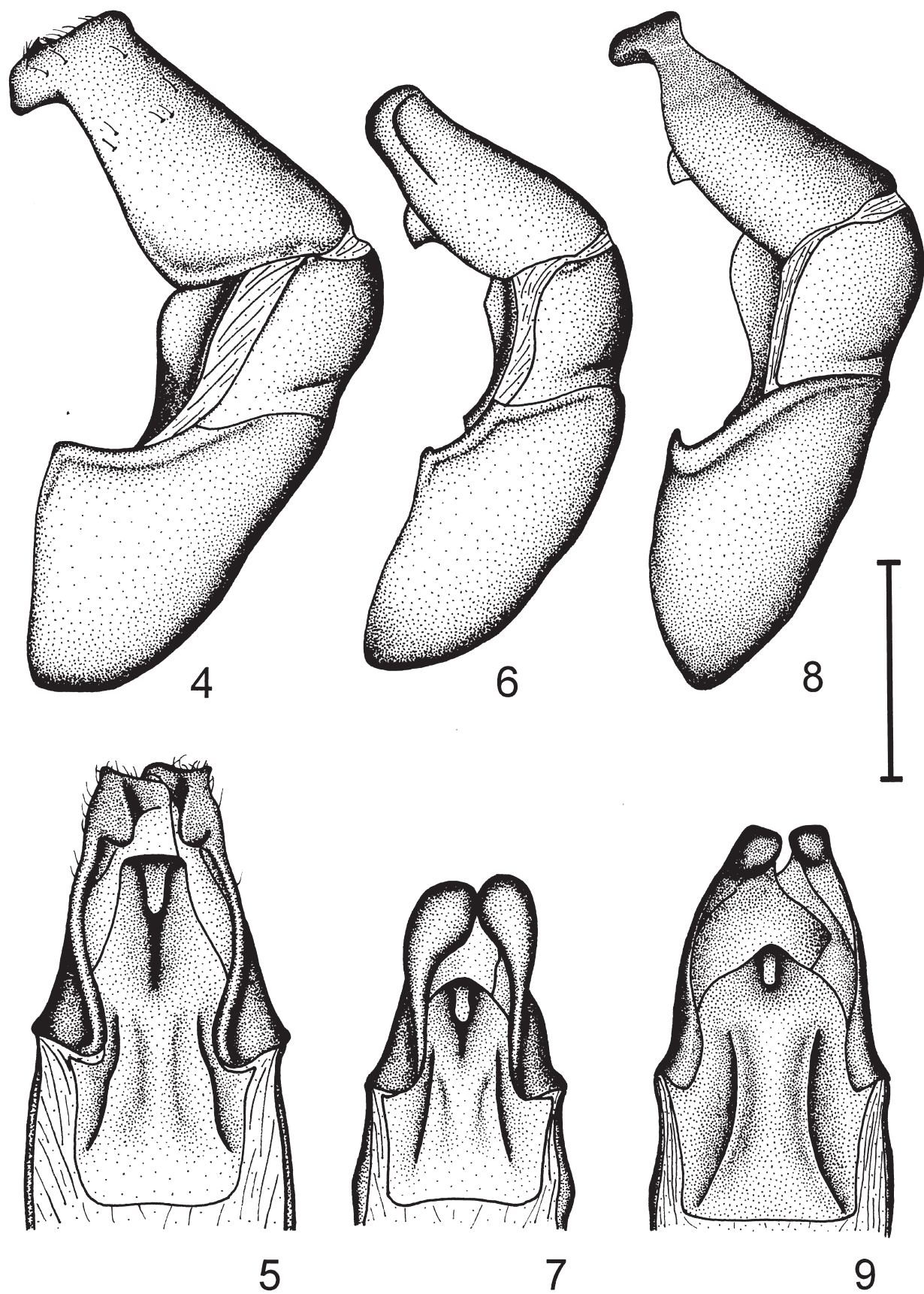

7

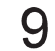

Fig. 4-5: Anomala parastasioides (holotype: Borneo, Sabah); Fig. 4: Aedeagus lateral; Fig. 5: Aedeagus ventral.- Fig. 6-7: Anomala matangensis (holotype: Borneo, Sarawak); Fig. 6: Aedeagus lateral; Fig. 7: Aedeagus ventral. - Fig. 8-9: Anomala fulvofusca (Sumatra-Utara, Sungei Kopas); Fig. 8: Aedeagus lateral; Fig. 9: Aedeagus ventral. 


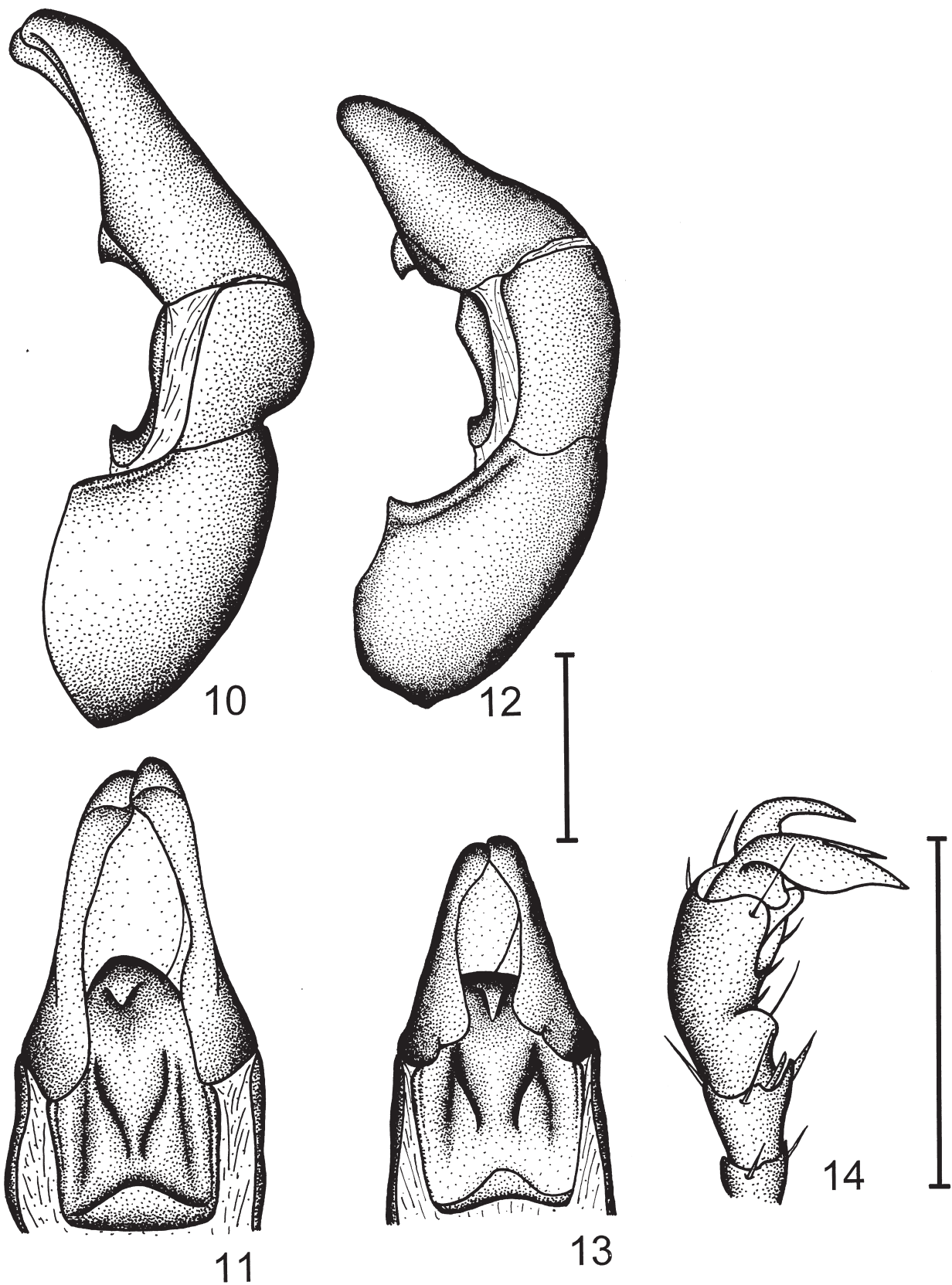

Fig. 10-11: Anomala pumilis (syntype: Borneo, Sabah); Fig. 10: Aedeagus lateral; Fig. 11: Aedeagus ventral. - Fig. 12-13: Anomala pumiloides (holotype: Borneo, Sabah); Fig. 12: Aedeagus lateral; Fig. 13: Aedeagus ventral. - Fig. 14: Anomala parastasioides (holotype: Borneo, Sabah), Protarsomeres 4-5; Scale line $=1 \mathrm{~mm}$. 


\section{Discussion}

Together with $A$. fulvofusca and $A$. pumilis the three new species form a monophyletic species group (fulvofusca-group), which is based on the combination of some significant and derived morphological characters of the male genitalia. The ventral plate shows two longitudinal ridges and is strongly narrowed into a backwards-pointed hook. In the lateral view there is always a distinct angle between phallobase and parameres (Figs 4-13). Moreover, the five species are exclusively characterized by the combination of the following characters: short and convex body shape; inner fore claw conspicuously modified with a small, spine-shaped upper branch in the male; pronotum with a complete basal marginal line; pygidium and metasternum with coarse umbilicate punctures. All five species of this group have been described from Borneo where speciation may have taken place. So far only $A$. fulvofusca has also been recorded from Sumatra (ZorN, 1998). The closest relatives outside of the fulvofusca-species group are yet unknown.

\section{Acknowledgements}

For their friendly help, for the loan of specimens and for allowing me to visit their institutions I am very grateful to Dr. M. Uhlig, Mr. J. Schulze and Mr. B. Jaeger (Museum für Naturkunde der HumboldtUniversität zu Berlin) and Mr. Malcolm Kerley (BMNH). I am especially indebted to my colleague and friend Milan Nikodym (Prague) from whom I have received the material of $A$. pumiloides.

\section{Literature}

Ohaus, F. 1915: XVII. Beitrag zur Kenntnis der Ruteliden (Col. lamell.). - Stettiner Entomologische Zeitung 76: 88-143.

Ohaus, F. 1932: Two new Species of Anomala from British N. Borneo and Sumatra in the British Museum. - The Annals and Magazine of Natural History including Zoology, Botany and Geology (series 10) 9: 405-406.

Westwood, J. O. 1842: Insectorum novorum Centuria. Decadis secundae, ex ordinae Coleopterorum, Synopsis. - The Annals and Magazin of Natural History 8: 203-205.

Zorn, C. 1998: Neue Arten des Genus Anomala Samouelle, 1819 von Sumatra und der Malayischen Halbinsel sowie Bemerkungen zur Synonymie und Verbreitung einiger Arten (Coleoptera: Melolonthidae: Rutelinae). - Beiträge zur Entomologie 48: 469-503.

Author's address:

CARSTEN Zorn

Sülzer Strasse 52

17179 Gnoien, Germany

e-mail: czorn70@hotmail.com
Subject editor:

Prof. Dr. B. KLAUSNitzer 